\title{
$\bullet$ Hung Up Reflex, Clincher to Hypothyroidism - A Case Report
}

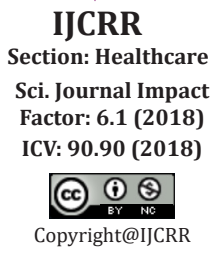

\section{Lohiya Sham1, Damke Sachin², Chaudhary Richa}

'Associate Professor, Dept of Paediatrics, J.N.M.C. Sawangi, Maharashtra, India; 'Professor and HOD, Department of Paediatrics, J.N.M.C. Sawangi, Maharashtra, India; ${ }^{3}$ Associate Professor, Department of Paediatrics, J.N.M.C. Maharashtra, India.

\section{ABSTRACT}

Introduction: Acquired Hypothyroidism is the most common endocrine abnormality in paediatrics. Clinical features are weight gain, constipation, cold intolerance.

Case Report: 10-year-old female child presented to the out-patient department with complaints of intermittent swelling all over the body which used to subside on its own in a week.

Result: On examination, bradycardia, decreased height velocity, hung up reflex. We describe a case of hypothyroidism suspected based on hung up reflex in knee jerk.

Conclusion: From the case report, it appears that we can monitor response to treatment by observing improvement in relaxation time of deep tendon reflex in addition to pulse rate, stool frequency and general well-being.

Key Words: Hypothyroidism, Hung up reflex, Bradycardia

\section{INTRODUCTION}

Hypothyroidism in paediatrics is usually diagnosed by the presence of typical symptoms like decreased activity, constipation, decreasing school performance. On examination, there is bradycardia, decreased growth velocity, sometimes goitre. Hung up reflex or woltman sign is not a common presentation but a very specific one. Hung up reflex (also called as Woltman sign or, myxedema reflex) is increased relaxation time of elicited deep tendon reflex. It is generally seen in ankle jerk. It is named after Henry Woltman, an American neurologist ${ }^{1}$. Here we present a case of hypothyroidism with a complaint not corroborative with the diagnosis. It was mainly suspected based on one clinical finding of hung up reflex. Also, videos show improvement in relaxation time of deep tendon reflex after starting thyroxine.

\section{CASE REPORT}

The 10-year-old female child presented to the out-patient department with complaints of intermittent swelling all over the body which used to subside on its own in a week. There was no other complaint. On examination, she was noted to have a height of $112 \mathrm{~cm}$ which was less than 3rd centile on Indian Academy of Pediatrics growth chart 2015. Her pulse rate was 72 per min but was relatively low volume pulse. On further examination her skin was dry. Her systemic examination was normal except in the central nervous system, deep tendon reflexes (DTRs) examination; slow relaxation was seen i.e. hung up reflex in knee jerk. Her higher mental function and intelligence quotient (I.Q.) appeared to be normal for her age. Based on clinical examination her thyroid function test was sent which showed Thyroid-stimulating hormone (TSH) to be more than $100 \mu \mathrm{IU} / \mathrm{ml} \mathrm{T} 41.83 \mu \mathrm{g} / \mathrm{dl}$ (Figure 1). The patient was started on thyroxine $5 \mu \mathrm{g} / \mathrm{kg} /$ day. On day 4 of starting thyroxine, there was an improvement in relaxation time in DTRs.

\section{Corresponding Author:}

Sham B. Lohiya, Department of Paediatrics, 3rd floor, A.V.B.R.H., Sawangi, Wardha, Maharashtra-442001, India. Mob: 8098842537; Email: sham.lohiya19@gmail.com

ISSN: 2231-2196 (Print)

Received: 19.07 .2020
ISSN: 0975-5241 (Online)

Revised: 08.10 .2020
Accepted: 02.11 .2020 


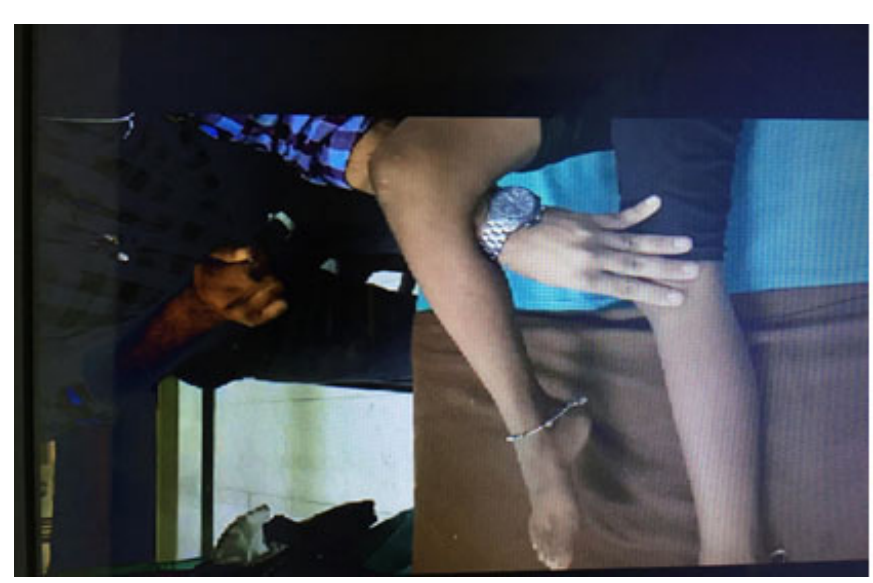

Figure 1: Deep tendon reflex; examination of knee jerk.

\section{DISCUSSION}

Hypothyroidism is the most common endocrine abnormality in the pediatric age group. From different types of hypothyroidism, congenital hypothyroidism is very crucial. Timely and appropriate therapy in congenital hypothyroidism can prevent brain damage and can salvage patient's I.Q. Congenital hypothyroidism is common in India with the frequency of it being 1 out of 2640 neonates. It is more common in India when compared with the worldwide incidence of 1 in 3800 newborns. Hypothyroidism occurs in pediatric age group too where it is mostly secondary to thyroiditis. ${ }^{1,2}$ In a clinic-based study from Mumbai, 800 children with thyroid disease were studied. Out of these, $79 \%$ of kids had hypothyroidism. Thyroid dysgenesis, dys-hormonogenesis, and thyroiditis were common causes of hypothyroidism. ${ }^{2}$ Also, there is a high prevalence of thyroid disorders in reproductive age group. ${ }^{6}$ The presence of goitre is one of the main complaints in hypothyroidism in the pediatric age group. Signs of hypothyroidism are: dull facies, stunted growth, disproportionate short structure, relative bradycardia, excess weight gain, coarse dry skin, carotenemia, hung up reflex (though not commonly seen in pediatric age group, maybe because it is generally overlooked ), goitre formation and myxedema.

Hung up reflex (Woltman sign) can be elicited in about $75 \%$ of cases of hypothyroidism patients though incidence in pediatric patients per se is unknown. It has a high positive predictive value of $92 \%$ for hypothyroidism. ${ }^{1}$ It is best seen in ankle jerk. ${ }^{3}$ In the normal individual, the relaxation time of deep tendon reflex is $240-320 \mathrm{~ms}$. Time taken for relaxation of deep tendon reflex tends to correlate with the severity of hypothyroidism. The step which affects the time for muscle relaxation is reuptake of calcium by the sarcoplasmic reticulum. This step is dependent on the calcium ATPase activity of the muscle fibre. Calcium adenyl pyrophosphatase (ATPase) activity of a fast-twitch variety of muscle fibre is decreased in hypothyroidism causing delayed relaxation, the hung up reflex. ${ }^{4}$ Hung-up Knee jerk reflex (HUKJR) is a classical clinical sign specific for Huntington's disease that can be observed along the disease course. ${ }^{5}$

In our case, hypothyroidism was suspected based on pulse and hung up reflex only, as there were no characteristic complaints of hypothyroidism. She was already worked up for nephrotic syndrome in previous hospital visits to another hospital. Hung reflex was checked in all upper and lower limb reflexes, but was most prominent in knee jerk, which is again different from previous literature. Any particular reason for this finding is not present as per our view. Hence we want to emphasize the importance of checking DTRs in suspected hypothyroidism or for that reason in any case. ${ }^{6}$ To best of our knowledge, this is a first pediatric case report with video of hung up reflex in hypothyroidism with improvement in relaxation time with treatment as early as day 4 .

\section{CONCLUSION}

In this case, hypothyroidism was suspected mainly based on DTRs. DTRs is generally overlooked in the pediatric examination. Hence it is recommended to do a complete physical examination irrespective of complaints. Also from case report, it appears that we can monitor response to treatment by observing improvement in relaxation time of deep tendon reflex in addition to pulse rate, stool frequency and general well-being.

\section{ACKNOWLEDGEMENT}

Authors acknowledge the immense help received from the scholars whose articles are cited and included in references to this manuscript. The authors are also grateful to authors/ editors/publishers of all those articles, journals and books from where the literature for this article has been reviewed and discussed.

\section{Conflict of interest: None.}

Financial support: None.

\section{REFERENCES}

1. Houston CS. The diagnostic importance of the myxoedema reflex (Woltman's sign). CMAJ 1958;78:108-12.

2. Desai PM. Disorders of the Thyroid Gland in India. Indian $\mathbf{J}$ Pediatr 1997;64:11-20.

3. Zulewski H, Müller B, Exer P, Miserez A, Staub J. Estimation of tissue hypothyroidism by a new clinical score. Evaluation of patients with various grades of hypothyroidism and controls. J Clin Endocrinol Metab 1997;82:771-6.

4. Duyff RF, Van den Bosch J, Laman DM, van Loon BJ, Linssen WH. Neuromuscular findings in thyroid dysfunction: a prospective clinical and electrodiagnostic study. J Neurol Neurosurg Psychiatr 2000;68:750-5. 
5. Perez-Perez J, Diaz-Manera J, Pagonabarraga J, Martinez-Horta S, Carceller M, Horta A, et al. Hung up knee jerk reflex in Huntington's disease: A clinical and neurophysiological study. Mov Disord 2017; 32.
6. Poonam Arora, Smita Prasad, Busi Karunanand. Hospital Based Study Of Thyroid Disorders In Rural Population Of Gurgaon, Haryana. Int J Curr Res Rev 2020;8(21):6-11. 